\title{
A OIT e o "contrato social": a importância de trabalhar por um futuro melhor
}

\author{
The ILO and the fulfillment of the "social contract": the importance of working \\ towards a better future
}

Kátia Magalhães Arruda*

\section{Resumo}

O presente artigo aborda, de forma proeminente, o histórico documento da OIT divulgado em seu centenário, intitulado "Trabalhar por um futuro melhor". Procura-se avaliar o atual momento histórico, com o avanço tecnológico e concentração de riqueza, ao mesmo tempo em que há avanço da desigualdade e precarização do trabalho, com forte impacto na vida dos trabalhadores. Resgata-se, ainda, a temática do contrato social como elemento de coesão social e construção da cidadania, a ser concebido tendo como foco central, o investimento nas pessoas e no trabalho digno e sustentável.

Palavras-chave: OIT. Contrato social. Trabalho digno. Tecnologia. Sustentabilidade.

\section{Abstract}

This article provides proeminent historical document of the ILO (International Labour Organization), published in this centenary year. Titled "Work for a brighter future", it aims to assess the current historical moment, with the advancement of technology and wealth concentration, while at the same time there is a breakthrough in inequality and the precariousness of work, with a significant impact on the lives of the workers. This article rescues the subject-matter of the social contract as an element of social cohesion and the construction of citizenship, to be conceived as having a central focus of attention, the investment in people and decent and sustainable work.

Keywords: OIT. Social contract. Decent work. Technology. Sustainability.

\section{Introdução}

Por ocasião da celebração dos 100 anos da Organização Internacional do Trabalho (OIT), foi elaborado um informe da Comissão Mundial sobre o Futuro do Trabalho, no qual os principais temas abordados buscam identificar os desafios da atualidade, bem como estabelecer parâmetros e propostas para dar cumprimento ao "contrato social" com engajamento e responsabilização de todos os organismos internacionais, Estatais e multilaterais, com agenda no ser humano. O documento foi intitulado "Trabalhar por um futuro melhor" e está centrado em três eixos de atuação, assim divididos:

1) Aproveitar o momento, contextualizado no atual período histórico;

2) O cumprimento do contrato social, ${ }^{1}$ subdividido em: a) aumentar o investimento na capacidade das pessoas; b) nas instituições do trabalho e c) no trabalho decente e sustentável, visando auxiliar na reversão dos prejuízos causados pelo aprofundamento da desigualdade, aproveitando os avanços tecnológicos e a conscientização ambiental para criar novas possibilidades, ao invés de diminuir ou precarizar postos de trabalho;

3) Assumir responsabilidades na concretização dos propósitos.

\footnotetext{
Doutora em Políticas Públicas pela Universidade Federal do Maranhão e Mestre em Direito pela Universidade Federal do Ceará. Ministra do Tribunal Superior do Trabalho e Professora titular do Programa de Mestrado em Direito e Relações Sociais e Trabalhistas e da graduação em Direito do UDF - Centro Universitário. Brasília - DF - Brasil. E-mail: gmka@tst.jus.br.

1 Aqui compreendido como um pacto de cooperação realizado entre os homens, que cedem parte da sua liberdade natural em prol de uma convivência harmoniosa em sociedade, regida pela vontade geral de todos. Embora para alguns o "contrato social" seja uma metáfora, para outros, tem sido um modo de regular a relação entre os homens, a sociedade e o Estado.
} 
Nesse contexto, a OIT aborda dois temas de extrema importância para o desenvolvimento: a consolidação do trabalho digno e a diminuição da desigualdade, ambos questionados e postos em crise à medida que o conceito sobre o que é uma sociedade justa vai se afrouxando em uma teia de desconstrução de direitos e aumento da pobreza.

Há, portanto, uma retomada aos temas essencialmente defendidos pela OIT desde a sua criação, em 1919, quando houve a adoção de seis convenções relativas à limitação da jornada de trabalho, à proteção à maternidade, à luta contra o desemprego, à idade mínima para o trabalho e à proibição do trabalho noturno para mulheres e menores de 18 anos. Duas grandes guerras marcaram a história e registraram a atuação firme da OIT, inclusive servindo como referência para a Carta das Nações Unidas (1946) e a Declaração Universal dos Direitos Humanos (1948), sendo a primeira agência especializada da Organização das Nações Unidas (ONU).

Em 1998, em sua Conferência Internacional, é adotada a "Declaração dos Direitos e Princípios Fundamentais do Trabalho", com quatro eixos fundamentais que nortearam todos os documentos subsequentes: a) o direito à liberdade sindical e à negociação coletiva; b) a eliminação de todas as formas de trabalho forçado; c) a abolição do trabalho infantil e d) a eliminação da discriminação no emprego e ocupação.

A partir do relatório da OIT, pretendemos analisar o atual momento vivido no mundo do trabalho e revisitar o tema do "contrato social", reconstruindo sua importância e vinculação com a busca da igualdade.

\section{0 atual contexto histórico}

Pierre Rosanvallon ${ }^{2}$ destaca que nunca vivemos em um tempo em que se falasse tanto nas desigualdades e se atuasse tão pouco para reduzi-las. Um tempo de grandes evoluções tecnológicas, sem que se tenha a certeza de que o homem continuará como elemento preponderante. Embora seja óbvio que a inteligência artificial e a robótica criarão novas performances no trabalho, também parece assustador saber que muitos perderão seus postos de trabalho e não terão chance sequer de acompanhar as novas tecnologias, pois suas competências e habilidades terão se tornado obsoletas.

Mais preocupante ainda é saber que o progresso tecnológico pode não guardar correspondência com o progresso social e que pode até agravar as diferenças. Dados estimam que $56 \%$ dos empregados podem ser automatizados nos próximos vinte anos, substituindo ou transformando o modo como esses trabalhos são realizados. $O$ avanço do teletrabalho, sem definição de jornada de trabalho, que antes de significava liberdade de horário, acabou por aprisionar ainda mais o trabalhador, enquanto liberta o empregador de várias responsabilidades que lhe competiam, como manter o ambiente de trabalho seguro e ecologicamente protegido. É possível presenciar a extensão de atividades terceirizadas e a troca do trabalho presencial pelo ciberproletariado, o trabalhador que lida com a informática, mas vivencia sua "desrealização, pela vivência da precarização" (ANTUNES, 2006, p. 25).

Mais do que isso, o excesso tecnológico, com a substituição dos homens, a exemplo do que pode ocorrer com a manipulação genética ou a contratação somente de "pessoas saudáveis", pode aniquilar um dos elementos mais importantes para a coesão da sociedade: a ajuda recíproca e a solidariedade para com os menos afortunados (SANDEL, 2013, p. 101). No texto "Trabalhar por um futuro melhor", da OIT, encontramos a seguinte citação:

Se se deixar que siga o seu curso atual, a economia digital provavelmente ampliará tanto as diferenças regionais como as de gênero e os sites de crowdworking e o trabalho mediado por aplicações que compõem a economia de plataformas digitais poderão recriar as práticas do século XIX e as futuras gerações de trabalhadores digitais. (OIT, 2019, p. 18).

A consolidação do trabalho digno, portanto, não parece um tema fácil, e as contradições se multiplicam: se, em algumas regiões, o desemprego é agravado pelas pressões migratórias e o crescimento da população

Pierre Rosanvallon é historiador francês, titular da cátedra de História Moderna e Contemporânea do Político do Collège de France, desde 2001. 
jovem, em outras, o envelhecimento da população causará danos no sistema de seguridade. Por um lado, o trabalho é essencial para a sobrevivência das pessoas, por outro lado, sua excessiva precarização torna-o perigoso, instável e desagregador, sobretudo quando o nível de desemprego aumenta e atinge milhões de pessoas. ${ }^{3}$

Segundo dados da OIT, 300 milhões de trabalhadores vivem em pobreza extrema, $36 \%$ da força de trabalho tem número excessivo de horas (mais de $48 \mathrm{~h} /$ semana), as mulheres recebem $20 \%$ a menos do que os homens, várias atividades são executadas com grandes riscos à saúde e com danos à vida e acidentes e, além disso, a desigualdade global tem crescido de forma acelerada (ricos cada vez mais ricos e em menor número) (OIT, 2019).

Lembrando o contexto histórico da Primeira Guerra Mundial, em 1919, com a fundação da OIT, pretende-se resgatar esse diálogo social, atrelado à Agenda 2030 das Nações Unidas para o Desenvolvimento Sustentável, que inclui o pleno emprego como objetivo a alcançar, juntamente com o trabalho digno e a justiça social. Marca o propósito de oportunizar a criação de trabalho digno, facilitar a passagem do emprego informal pelo formal e acabar a pobreza no trabalho.

Como afirma Wandelli (2015), focado na análise de Dejours, ${ }^{4}$ embora o mundo do trabalho não seja isento de riscos, já que pode gerar ou agravar problemas de saúde e exposição à violência (sobretudo nas atividades perigosas ou insalubres), o trabalho atua como vetor privilegiado do desenvolvimento humano, em sentido muito mais amplo do que a mera questão financeira, pois atua na definição da personalidade, autoestima, reconhecimento social, saúde psíquica, ampliando efeitos para o próprio aprendizado ético e político de cidadania, ou seja:

\begin{abstract}
Mais que poder gerar o melhor, o trabalho é condição de possibilidade para que isso ocorra. Essa é a tese da centralidade antropológica do trabalho. $O$ trabalho, como conjunto de atividades e relações, constitui-se em uma mediação essencial para autorrealização humana em temos de autonomia, saúde, ética e política. Retomando-se, assim, os passos iniciais desta exposição, percebe-se que, à luz da noção jurídica de dignidade humana, a essa centralidade antropológica deve corresponder uma centralidade jurídica do trabalho. (WANDELLI, 2015, p. 198).
\end{abstract}

De fato, a temática é relevante, pois devolve a centralidade do trabalho no processo produtivo e a preocupação com o ser humano. Resta saber se, na sociedade atual, prevalecerá a ótica excludente e individualista ou a ótica da solidariedade, que, assim como a fraternidade, pode ser tratada como categoria política capaz de "refundar a prática democrática, ao compatibilizar o relacionamento entre a igualdade (paridade) e a liberdade (diferença), em prol de uma causa unificante" (FONSECA, 2019, p. 55), uma vez que há o real temor de aumento e descontrole das jornadas de trabalho, em face dos trabalhos fora do escritório ou do "chão de fábrica", e sem limitação de horário, já que todas as informações requeridas, muitas vezes, cabem em um smartphone.

\title{
3 Pilares de ação para uma agenda centrada no ser humano
}

Para fortalecer o contrato social, a OIT propõe uma agenda que retome o papel do trabalhador e das pessoas como centro das políticas econômicas e sociais, com três eixos principais.

\subsection{Aumentar o investimento nas pessoas}

Tal investimento não se restringe à qualificação ou ampliação de aptidões dos trabalhadores. Visa à melhoria das condições de vida em um ambiente favorável, incluindo a aprendizagem desde a juventude, com a continuidade ou reinserção dos mais idosos no mercado de trabalho. Também inclui a implementação 
da igualdade de gênero e eliminação da violência e assédio no local de trabalho, com políticas de igualdade salarial e proteção social universal e efetiva para as pessoas vulneráveis, complementadas por um regime de maior seguridade e segurança social.

No que se refere à igualdade de gênero, dois aspectos merecem destaque: as mulheres realizam $3 / 4$ de todo o trabalho não remunerado, o que demonstra que a distribuição das tarefas domésticas ainda não é uma realidade na maioria dos lares. Além disso, não há igualdade salarial e poucos países adotam medidas transparentes de medição dessa igualdade. O uso de algoritmos no preenchimento de vagas de emprego pode perpetuar a discriminação e diminuir as oportunidades das mulheres, principalmente para as que são mães.

\subsection{Aumentar o investimento nas instituições do trabalho}

Na compreensão do fortalecimento dessas instituições, clama a OIT pela adoção de uma garantia laboral universal focada nos direitos fundamentais, com destaque para a questão salarial (que assegura condições de subsistência), a jornada com limites razoáveis e a questão da saúde e segurança no local de trabalho, independente de serem trabalhadores diretos ou indiretos, a tempo completo ou parcial, e, ainda, se o local de trabalho ocorre na empresa ou em sua residência.

Entre os direitos fundamentais a serem universalmente reconhecidos estão: a proibição do trabalho infantil ou forçado, a liberdade sindical, o reconhecimento à negociação coletiva e a política efetiva de não discriminação, todos em contexto de reforço mútuo. Assim, os limites na jornada de trabalho tendem a reduzir os riscos de acidentes de trabalho, o salário adequado tende a evitar o trabalho forçado e infantil (ao garantir melhor situação financeira para família), a proteção à saúde do trabalhador tende a diminuir o ônus da seguridade social e a liberdade sindical tende a fortalecer o diálogo social.

Um aspecto de extrema relevância está relacionado a reforçar a soberania dos trabalhadores sobre o tempo, uma vez que as lutas históricas pela diminuição da jornada de trabalho parecem esquecidas pelas mudanças tecnológicas. Computadores, tablets e celulares permitem que o empregado seja acionado a qualquer tempo e hora, diluindo a separação entre trabalho e vida pessoal, dificultando a delimitação do número de horas dedicadas à empresa e, até mesmo, da privacidade do trabalhador, que pode ser mais controlado hoje (pelos meios digitais) do que foi no passado (por meio de "cartões de ponto" ou mesmo do "ponto eletrônico").

O trabalhador atual pode ser acionado a qualquer momento, o que implica, na maioria das vezes, excessivo número de horas de trabalho e baixíssimo tempo para lazer ou outras atividades de sua vida pessoal. O trabalho se expande da empresa para a casa do trabalhador, de seus familiares, seus amigos ou qualquer outro lugar onde seja possível contatá-lo pela internet. Isso para não falar na substituição do trabalho humano por robôs, a exemplo do que ocorre com o entregador de pizzas ou pequenas mercadorias, substituído por drones. Como assinala a OIT (2019, p. 41):

Os trabalhadores e trabalhadoras precisam de maior soberania sobre o seu tempo. A capacidade de exercer maior escolha e controlo sobre as suas horas de trabalho melhorará a sua saúde e o seu bem-estar, bem como o desempenho individual e o da empresa. Os governos, os empregadores e os trabalhadores devem esforçar-se por acordar sobre a organização do tempo de trabalho que permita aos trabalhadores e trabalhadoras escolher os seus horários de trabalho, respeitando as necessidades que a empresa tenha de maior flexibilidade. O diálogo social é uma ferramenta importante para definir tempos de trabalho inovadores, adaptados às necessidades dos trabalhadores e dos empregadores.

Nesse tópico também é relevante o desenvolvimento das instituições oficiais, tais como fiscalização do trabalho e atuação do Ministério Público e do Poder Judiciário, pois, embora a atuação dos entes privados seja imprescindível, nada obstará que o predomínio do poder econômico dos empregadores e suas associações venha a enfraquecer a atuação dos sindicatos dos trabalhadores se não existirem mecanismos de fiscalização dos direitos individuais e sociais relacionados ao trabalho. 
É evidente que, em períodos de depressão econômica, em que os sindicatos nada podem fazer contra o desemprego, cresce a atuação meramente defensiva, ao invés da atuação propulsora de ampliação de direitos. Nas últimas décadas, os sindicatos têm sido atacados em sua autonomia e atuação política, o que demonstra que a "existência de um sindicato, seja qual for o grau de colaboracionismo dos líderes sindicais, reafirma a intransponível diferença entre o capital e o trabalho" (ALVES, 2003, p. 339), ou seja, o valor inestimável da organização dos trabalhadores. A despeito disso, a atuação sindical, reconhecidamente, tem limites, e esperar que só os sindicatos atuem em defesa dos trabalhadores é enfraquecer o conteúdo normativo que se pretende proteger, principalmente diante da fragmentação da representação sindical e da necessidade de sobrevivência sofrida pelos trabalhadores em tempos de crise e desemprego em massa.

\title{
3.3 Aumentar o investimento no trabalho digno e sustentável
}

Aliada com a agenda do trabalho digno e a meta do pleno emprego, persiste a recomendação de estimular áreas da economia com importância estratégica e investir na economia verde, sem a degradação ambiental, explorando setores de energia renovável, melhorando e modernizando a agricultura que, mundialmente, representa mais de dois em cada cinco trabalhadores, muitos dos quais ainda vivem na pobreza e sem acesso às novas tecnologias e à infraestrutura adequada, que inclui as vias de transporte, comunicação, escolas e serviços públicos.

\begin{abstract}
As redes inadequadas de transporte restringem a mobilidade da mão-de-obra, impedem o comércio e acentuam a divisão urbano-rural, a habitação insuficiente e precária aumenta o risco de acidentes e doenças; as escolas, as instituições técnicas e de formação profissional de má qualidade dificultam a criação de uma geração futura de talentos; e nos países em desenvolvimento, a falta de serviços básicos como água, energia, saneamento e assistência médica, acentua o fardo que recai sobre as mulheres e reduz a sua participação no mercado de trabalho. (OIT, 2019, p. 50).
\end{abstract}

Amartya Sen defende que a expansão de serviços, como educação, saúde e saneamento, pode contribuir para o desenvolvimento econômico e para a redução de taxas de mortalidade, de analfabetismo e criação de empregos de qualidade. Cita, para tanto, o exemplo do Japão, favorecido pelo desenvolvimento dos recursos humanos e que, ao expandir em massa a educação e a saúde (antes mesmo de romper com a pobreza), acabou por intensificar a afluência econômica, melhorando a situação do país como um todo (SEN, 2010, p. 62).

De todo modo, a OIT propõe que sejam reformulados os indicadores de medição do progresso, buscando-se caminhar em direção ao bemestar, à sustentabilidade e à igualdade, com as empresas assumindo uma maior responsabilidade social. Necessário, também, estender a compreensão de que somente o produto interno bruto (PIB) não consegue medir os avanços econômicos e sociais relevantes ao desenvolvimento da sociedade, inclusive por não captar indicadores relacionados ao meio ambiente e saneamento, devendo-se incluir dimensões que representem equidade, como o acesso à educação, à saúde e à habitação.

Sobre a responsabilidade social das empresas, há de se estimular coerência entre o discurso e a prática, evitando o que se costuma chamar de "código de ética duplo", no qual se defende a gestão de qualidade, mas se adota a prática de corrupção; ainda, aplica o "código de responsabilidade social em seus países sedes e outro, diferente, nos países em desenvolvimento" (SEN, 2010, p. 364) ou aplicam normas avançadas em suas matrizes e empregam mão de obra infantil e devastam o meio ambiente.

\section{A revitalização do contrato social}

No prefácio de Afonso Bertagnoli à edição da coleção universidade do livro "O contrato social", de Jean-Jacques Rousseau, é feito uma abordagem diversificada do sentido jurídico e filosófico de contrato, sendo o primeiro visto como uma convenção entre pessoas que se comprometem a dar, fazer ou não fazer; e, o segundo, um sentido de interesses bilaterais ou multilaterais para a realização de compromissos recíprocos. Já o sentido de "contrato social" de Rousseau tem relação com o tema do pacto social, portanto, 
conjunto de convenções fundamentais que estão implícitas ou explícitas na vida em comunidade, sob a direção de uma vontade geral que permita a boa convivência na sociedade. ${ }^{5}$

O pacto social atua como uma convenção capaz de tornar iguais em direito o que a natureza ofereceu em desigualdade física (e de poder) aos homens, a fim de alcançar a vontade geral, a conservação dos contratos e o bem comum. Assim como a natureza dá a cada homem um poder sobre os outros, o pacto social dá ao corpo político um poder sobre a sociedade. Portanto, faz parte do pacto social estabelecer entre os cidadãos a igualdade, em que todos se obrigam sob as mesmas condições e devem gozar dos mesmos direitos. (ROUSSEAU, 1988, p. 49).

O que fazer, entretanto, quando se aprofundam as desigualdades ${ }^{6}$ e agoniza o diálogo necessário ao pacto social, como ocorre na atualidade?

É certo que a garantia de igualdade se dá pela preservação de direitos, e que a ideia de cidadania implica em inclusão (na sociedade, no Estado, na política), algo bem diferente do que se verifica quando a regra dominante é a exclusão (pelo desemprego, pela ausência de saúde básica, pela discriminação).

Ocorre que, no contrato social, os homens renunciam a alguns direitos em prol de outros direitos, como uma vida confortável, em que não tenha que lutar diariamente para não morrer. Mas se o Estado (soberano) não lhe garante esse direito básico, poder-se-á romper esse contrato, iniciando-se um período de desobediência e guerra, como alerta Agostinho Ramalho Marques Neto (2014, p. 11):

\begin{abstract}
Se, hoje, Hobbes chegar aqui para ser indagado sobre se, no Brasil, temos o direito legítimo de destituir o soberano, com certeza dirá sim, porque, exatamente, a função do soberano, que é garantir o pacto e, garantindo o pacto, assegurar os meios para viver de uma maneira minimamente confortável, exatamente isso é negado numa situação como a nossa.
\end{abstract}

O que propõe a OIT é a retomada do diálogo em torno do contrato (pacto) social, para que o mundo caminhe para um tempo de maior igualdade, oportunidades sociais e inclusão das pessoas, perspectiva para a qual é absolutamente essencial a valorização da pessoa humana e do trabalho por ela produzido.

Na prática, há um "contrato social" no mundo do trabalho que necessita da atuação dos governos e das organizações de empregadores e trabalhadores na construção do diálogo. Retirar ou restringir o diálogo social é prejudicial à consolidação desse contrato por enfraquecer a legitimidade das condutas e decisões adotadas, o que pode causar o esgotamento do Estado de direito e da democracia, como afirma Rawls (1997, p.247):

Historicamente, um dos principais defeitos do governo constitucional tem sido a sua incapacidade de assegurar o valor eqüitativo da liberdade política. As medidas corretivas necessárias não têm sido tomadas; na verdade, parece que nunca foram consideradas seriamente. Disparidades na distribuição da propriedade e riqueza que em muito excedem o que é compatível com a liberdade política têm sido geralmente toleradas pelo sistema legal. Recursos públicos não têm sido empregados a fim de manter as instituições exigidas para garantir o valor eqüitativo da liberdade política.

O enfraquecimento das organizações dos trabalhadores e dos direitos por eles conquistados contribui para debilitar a democracia e aprofunda as desigualdades locais e mundiais à medida que agrava a concentração do poder econômico. Não é demais lembrar que "as desigualdades econômicas só são admissíveis até o ponto que não ameaçam a convivência entre as pessoas e a sociedade ou poder-se-á romper o pacto." (ROSANVALLON, 2012, p. 27).

\footnotetext{
5 No texto "Trabalhar por um futuro melhor" da OIT é feito um esclarecimento sobre o gênese do termo "contrato social" em autores como Thomas Hobbes (1651), John Locke (1690), Jean-Jacques Rousseau (1762) e, no século XX, John Rawls (1971).

6 "Concebo, na espécie humana, duas espécies de desigualdade: uma a que chamo natural ou física, por ser estabelecida pela natureza, e que consiste na diferença das idades, da saúde, das forças do corpo e das qualidades do espírito ou da alma; a outra, a que se pode chamar desigualdade moral ou política, por depender de uma espécie de convenção a ser estabelecida, ou pelo menos autorizada, pelo consentimento dos homens, esta consiste, nos diferentes privilégios que alguns usufruam em prejuízo dos outros, como serem mais ricos, mais reverenciados e mais poderosos do que eles, ou mesmo em se fazerem obedecer por eles". (ROUSSEAU, 1999, p. 159).
} 


\section{Considerações finais}

"Trabalhar por um futuro melhor" é um documento importante por vários motivos, principalmente por evidenciar um projeto voltado para o trabalho decente no centenário da Organização Internacional do Trabalho e por reafirmar o papel do ser humano como centro de toda política de mudança, política, tecnológica ou social.

Muitos poderão dizer que é utópico ou superficial, por não enfrentar grandes questões, como as causas da pobreza, da desigualdade ou mesmo degradações modernas, como o fenômeno da uberização, ${ }^{7}$ tratando-se apenas de um roteiro teórico para amenizar os confrontos modernos. Ou, talvez, a crítica seja firme no sentido da impossibilidade de pactos sociais em sociedades tão estratificadas e agudizadas por conflitos de classes.

Ambos estão certos: os que enaltecem e os que criticam. De fato, um mero documento publicado por uma instituição centenária não é capaz de mudar a realidade social, mas vivemos em um tempo em que defender o direito do trabalho é tido como obsoleto, falar de normas internacionais de proteção é paradoxal e preservar o diálogo social é profundamente desafiador diante da polarização que impede o caminhar no reconhecimento de direitos e cidadania.

Como afirma o cantor Gonzaguinha: "memória de um tempo onde lutar por seu direito é um defeito que mata... São tantas lutas inglórias". ${ }^{8}$

Justifica-se, portanto, a imediata retomada do tema do trabalho digno, acompanhado de temas vitais (como preservação do meio ambiente, tecnologia para todos, saúde e segurança dos trabalhadores), como componentes essenciais ao desenvolvimento, vistos em sua concepção plena de inclusão e melhoria das condições sociais para todas as pessoas.

\section{Referências}

ALVES, Giovanni. Limites do sindicalismo: Marx, Engels e a crítica da economia política. Bauru: Praxis, 2003.

ANTUNES, Ricardo (org.). Riqueza e miséria do trabalho no Brasil. São Paulo: Boitempo, 2006.

DEJOURS, Christophe. A banalização da injustiça social. 7. ed. Rio de Janeiro: FGV, 2012.

FONSECA, Reynaldo Soares da. O princípio constitucional da fraternidade: seu resgate no sistema de justiça. Belo Horizonte: D'Plácido, 2019.

MARQUES NETO, Agostinho Ramalho. O poder judiciário na perspectiva da sociedade democrática o juiz-cidadão. Revista Trabalhista - ANAMATRA, Brasília, v. 21, p. 30-50, 1994.

ORGANIZAÇÃO INTERNACIONAL DO TRABALHO. Trabalhar por um futuro melhor: Comissão Mundial sobre o futuro do trabalho. Oficina Internacional do Trabalho. Genebra: OIT, 2019.

POCHMANN, Márcio. A terceirização e a uberização do trabalho no Brasil. Blog da Boitempo, [São Paulo], 24 ago. 2016. Disponível em: https://blogdaboitempo.com.br/2016/08/24/a-terceirizacao-e-auberizacao-do-trabalho-no-brasil/. Acesso em: 24 ago. 2016.

RAWLS, John. Uma teoria da justiça. 2. ed. São Paulo: Martins Fontes, 1997.

ROSANVALLON, Pierre. La sociedad de iguales. Buenos Aires: Manantial, 2012.

ROUSSEAU, Jean-Jacques. Discurso sobre a origem e os fundamentos da desigualdade entre os homens. 2. ed. São Paulo: Martins Fontes, 1999.

Embora o termo se estabeleça a partir da empresa "Uber", expõe uma tendência de flexibilização trabalhista em que o trabalhador assume os riscos de seu empreendimento, distanciado de controle de jornada e das normas básicas de saúde e segurança do trabalho, e distanciando-se, crescentemente, da regularidade do assalariamento formal e da garantia dos direitos sociais e trabalhistas, como afirma Pochmann (2016).

8 Música "Pequena memória para um tempo sem memória". 
ROUSSEAU, Jean-Jacques. O contrato social: princípios de direito público. Tradução: Antônio de P. Machado. Rio de Janeiro: Ediouro, 1988.

SANDEL, Michael. Contra a perfeição: ética na era da engenharia genética. Tradução: Ana Carolina Mesquita. Rio de Janeiro: Civilização Brasileira, 2013.

SEN, Amartya. Desenvolvimento como liberdade. Tradução: Laura Teixeira Motta. São Paulo:

Companhia das Letras, 2010.

SEN, Amartya; KLIKSBERG, Bernardo. As pessoas em primeiro lugar: a ética do desenvolvimento e os problemas do mundo globalizado. São Paulo: Companhia de Letras, 2010.

WANDELLI, Leonardo. Da psicodinâmica do trabalho ao direito fundamental ao conteúdo do próprio trabalho e ao meio ambiente organizacional saudável. Revista Eletrônica do curso de Direito da UFSM, Santa Maria, v. 10, n. 1, p. 193-217, 2015. Disponível em: https://periodicos.ufsm.br/revistadireito/ article/view/19239. Acesso em: 10 jul. 2019.

Recebido em: 11/09/2019

Aprovado em: 17/11/2019 